\title{
What is new in Purinergic Signaling and Cervical Cancer?
}

\author{
Andréia Machado Cardoso1*, Maria Luiza Mukai Franciosi2, Adriana Wagner3* \\ ${ }^{1}$ Graduate Program in Biomedical Sciences, Medicine Course, Member of the Brazilian Purine Club, Federal University of Fronteira Sul, Campus \\ Chapecó, Santa Catarina, Brazil \\ ${ }^{2}$ Medicine Course, Federal University of Fronteira Sul, Campus Chapecó, Santa Catarina,Brazil \\ ${ }^{3}$ Medicine Course, Federal University of Fronteira Sul, Campus Chapecó, Santa Catarina, Brazil; PhD in Medicine (UNIFESP); Gynecologist and \\ obstetrician in the public health service of Chapecó, SC, Brazil. \\ * Corresponding Author: Andréia Machado Cardoso, Graduate Program in Biomedical Sciences, Medicine Course, Member of the Brazilian Purine \\ Club, Federal University of Fronteira Sul, Campus Chapecó, Santa Catarina, Brazil.
}

Received date: May 03, 2021; Accepted date: May 11, 2021; Published date: May 14, 2021

Citation: Andréia M Cardoso, MLM Franciosi, A Wagner. (2021) What is new in Purinergic Signaling and Cervical Cancer?. Cancer Research and Cellular Therapeutics. 5(2); Doi: 10.31579/2640-1053/084

Copyright: (C) 2021, Andréia Machado Cardoso, This is an open access article distributed under the Creative Commons Attribution License, which permits unrestricted use, distribution, and reproduction in any medium, provided the original work is properly cited.

\begin{abstract}
Since our publication "Purinergic Signaling and Tumor Microenvironment in Cervical Cancer" [1], in early 2020, there has been a significant change in purinergic signaling research. The Coronavirus disease 2019 (COVID-19) significantly impacted the prevention, diagnosis, and treatment of cervical cancer [2]. In that previous review, we had addressed the possibilities of purinergic signaling in the tumor microenvironment of this type of cancer [1]. The conclusions were: the extracellular medium of cervical cancer is rich in adenosine triphosphate (ATP) and adenosine $[3,4,5]$; ATP is a pro-inflammatory molecule that has an affinity for P2X2, $\mathrm{P} 2 \mathrm{X} 4$, and $\mathrm{P} 2 \mathrm{X} 7$ receptors [6]; this activation leads to apoptosis of the cells of the cervix [7]; P2X7 is still involved in stimulating factors that lead to mitogenic and angiogenic pathways [8]; there is a variant of P2X7 in cervical cancer cells, $\mathrm{P} 2 \mathrm{X} 7 \mathrm{j}$, which decreases permeability and cell death $[9,10,11]$. The P2Y1, P2Y2, and P2Y6 receptors, in turn, have the effect of tumor progression [12]. The review also contributed to the understanding of adenosine, which would activate A2A receptors on T lymphocytes, which would promote a decrease in the proliferation and effector function of such cells [13].
\end{abstract}

Keywords: purinergic signaling; cervical cancer; tumor microenvironment

\section{Introduction}

Since our publication "Purinergic Signaling and Tumor Microenvironment in Cervical Cancer" [1], in early 2020, there has been a significant change in purinergic signaling research. The Coronavirus disease 2019 (COVID-19) significantly impacted the prevention, diagnosis, and treatment of cervical cancer [2]. In that previous review, we had addressed the possibilities of purinergic signaling in the tumor microenvironment of this type of cancer [1]. The conclusions were: the extracellular medium of cervical cancer is rich in adenosine triphosphate (ATP) and adenosine $[3,4,5]$; ATP is a pro-inflammatory molecule that has an affinity for $\mathrm{P} 2 \mathrm{X} 2, \mathrm{P} 2 \mathrm{X} 4$, and $\mathrm{P} 2 \mathrm{X} 7$ receptors [6]; this activation leads to apoptosis of the cells of the cervix [7]; P2X7 is still involved in stimulating factors that lead to mitogenic and angiogenic pathways [8]; there is a variant of $\mathrm{P} 2 \mathrm{X} 7$ in cervical cancer cells, $\mathrm{P} 2 \mathrm{X} 7 \mathrm{j}$, which decreases permeability and cell death $[9,10,11]$. The P2Y1, P2Y2, and P2Y6 receptors, in turn, have the effect of tumor progression [12]. The review also contributed to the understanding of adenosine, which would activate $\mathrm{A} 2 \mathrm{~A}$ receptors on $\mathrm{T}$ lymphocytes, which would promote a decrease in the proliferation and effector function of such cells [13].

In 2020 and 2021, two other studies on the thematic purinergic system and cervical cancer were published. The article "Extracellular ATP Mediates Cancer Cell Migration and Invasion through Increased
Expression of Cyclooxygenase 2", by Sharma, Kalra, and Akundi (2021), applied HeLa cells (which come from cervical cancer), and this study associated the protein inflammatory cyclooxygenase $2(\mathrm{COX}-2)$ to metastatic progression. This research also revealed high levels of ATP in the tumor microenvironment of cervical cancer and increased cell death from the use of doxorubicin, which is a chemotherapeutic agent. In addition, the authors addressed that the P2Y12 purinergic receptor is important for modulating cell migration and tumor invasion and that blocking such receptors would decrease COX-2 invasion and expression. Another receptor studied was P2X7, in which this study conducted its antagonism through A740003, and this decreased ATP-mediated invasion [14], as proposed in the review by Pfaffenzeller, Franciosi, and Cardoso (2020) [1]. The main contribution of this article was the correlation between the purinergic system and inflammatory pathways, in addition to observing the action of purinergic receptors with the use of antagonists [14].

The other publication related to the theme addressed is "Detection of CD39 and a highly glycosylated isoform of CD73 soluble in the plasma of patients with cervical cancer: correlation with disease progression", Muñóz-Godínez et al. (2020). This study aimed to determine whether ectonucleotidases CD39 and CD73, which contribute to the production of adenosine from ATP dephosphorylation, are involved in the progression of cervical cancer. For this purpose, platelet-free plasma was compared 
between groups of patients with: low-grade intraepithelial lesions ( $\mathrm{n}=$ $18)$; high-grade squamous intraepithelial lesions $(\mathrm{n}=12)$; cervical cancer $(n=19)$; and normal donors $(n=15)$. The concentration of CD39 and CD73 increased concomitantly with the progression of the disease, which means that the increased expression of these ectonucleotidases and the concentration of adenosine no tumor microenvironment can be related to the progression of cervical cancer [15]. Figure 1 compiles the updates related to the theme of cervical cancer and purinergic system.

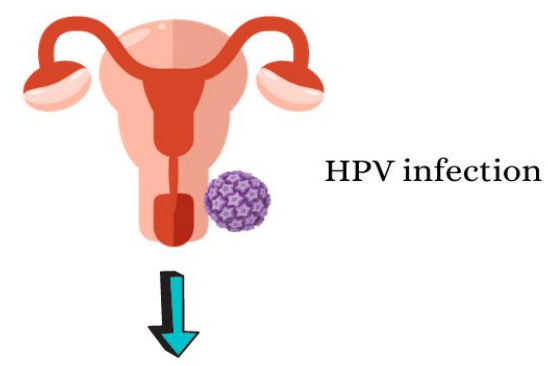

High levels of ATP in the tumor microenvironment of cervical cancer

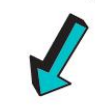

cOX-2 activation

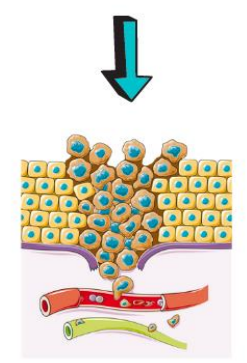

Metastasis

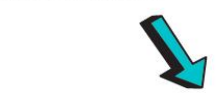

CD39 e CD73 increase

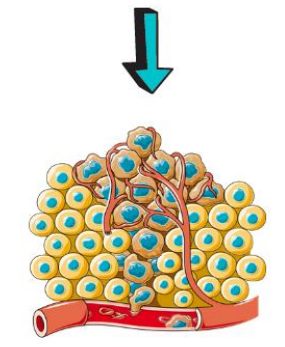

Tumor progression

Figure 1: Uptodates in cervical cancer and purinergic signaling. The HPV infection promotes the high levels of ATP in the tumor microenvironment of cervical cancer. This process stimulates COX2, which leads to metastasis. The ectonucleotidases CD39 and CD79 are at high levels and lead to the degradation of ATP in adenosine, which performs tumor progression. HPV: Human Papilomavirus.

\section{Purinergic Signaling and COVID-19 Pandemic}

The coronavirus disease (COVID-19), caused by SARS-CoV-2 infection, accounts for more than 2.4 million deaths worldwide, making it the main public health problem in 2020 and 2021 [16]. Some reviews suggest the possible role of purinergic signaling in COVID -19 infection. During the viral infections, the ATP could be released, and this molecule initiates a cascade that activates purinergic receptors, such as $\mathrm{P} 2 \mathrm{X} 7$ (like in cervical cancer). The receptor activation enhances the proinflammatory state in the respiratory cells. Besides, ATP is involved in the stimulation of the immune cells, such as macrophages and neutrophils. In this way, some researchers wrote about possibility of purinergic receptors in the COVID19 treatment $[17,18,19,20]$.

\section{Cervical Cancer and COVID-19 Pandemic}

The COVID-19 pandemic can affect cervical cancer prevention (through the application of vaccines), screening (Pap smear), and treatment [21]. This type of cancer is the fourth most prevalent in the world female population and there is concern about its evolution during the pandemic [22]. The radiotherapy operation is the main of the articles which addressed the theme. Radiotherapy can be safely administered during this time. The hypofractionated radiotherapy use can reduce the number of visits to the service. These rearrangements make the radiotherapy work would avoid potentially fatal delays in the provision of cancer care. Besides, this treatment also does not compete with the resources associated with the care of COVID-19, such as the use of respirators or beds in the intensive care unit (ICU). Also, there are stagings of cervical cancer that the best indication would be radiotherapy. The use of personal protective equipment (PPE) ensures a safe provision of care, both for the patient and the health team. During the pandemic, it is important to balance the risks of infection with the increased risks of cancer mortality from postponing treatment [21, 23-25].

Regarding screening and diagnosis, the American Society of Colposcopy and Cervical Pathology has published guidance for the management of screening tests for cervical cancer during the pandemic and the general suspension of elective procedures. This includes: postponing colposcopy for patients with low-grade intraepithelial lesions for up to 6 to 12 months; potential postponement of diagnostic or excision procedures for patients with suspected high-grade intraepithelial lesions for up to 3 months; and attempted evaluation of those suspected of having invasive disease within 4 weeks of the initial results of the pathology [21, 23-25].

The service's priorities are for the treatment of cervical cancer: patients with cervical cancer in the initial stage of surgery and radiotherapy are therapeutic therapy; for locally advanced cervical cancer, treatment is definitive chemoradiation; for patients with metastatic cervical cancer, first-line chemotherapy (such as bevacizumab) should also be considered 
a priority treatment. It is important to note that cancer treatment may represent an urgency rather than an elective procedure [25].

\section{References}

1. Pfaffenzeller MS, Franciosi ML, Cardoso AM. (2020) Purinergic signaling and tumor microenvironment in cervical Cancer. Purinergic Signalling. 13:1-3.

2. Richards M, Anderson M, Carter P, Ebert BL, Mossialos E. (2020) The impact of the COVID-19 pandemic on cancer care. Nature Cancer. 565-567.

3. Di Virgilio F, Sarti AC, Falzoni S, De Marchi E, Adinolfi E. (2018) Extracellular ATP and P2 purinergic signalling in the tumour microenvironment. Nature Reviews Cancer. 18(10):60118.

4. Gao ZW, Dong K, Zhang HZ. (2014) The roles of CD73 in cancer. BioMed research international.

5. Di Virgilio F. (2012) Purines, purinergic receptors, and cancer. Cancer Research. 72(21):5441-7.

6. Ferrari D, Malavasi F, Antonioli L. (2017) A purinergic trail for metastases. Trends in Pharmacological Sciences. 38(3):277-90.

7. de Andrade Mello P, Coutinho-Silva R, Savio LE. (2017) Multifaceted effects of extracellular adenosine triphosphate and adenosine in the tumor-host interaction and therapeutic perspectives. Frontiers in Immunology. 8:1526.

8. Bastid J, Cottalorda-Regairaz A, Alberici G, Bonnefoy N, Eliaou JF, Bensussan A. (2013) ENTPD1/CD39 is a promising therapeutic target in oncology. Oncogene. 32(14):1743-51.

9. Wang YY, Bai ZL, He JL, Yang Y, Zhao R, Hai P, et al. (2016) Prognostic value of neutrophil-related factors in locally advanced cervical squamous cell carcinoma patients treated with cisplatinbased concurrent chemoradiotherapy. Disease markers. 2016:3740794.

10. Gorodeski GI. (2004) Estrogen Attenuates P2X7-R - Mediated Apoptosis of Uterine Cervical Cells by Blocking Calcium Influx. Nucleosides, Nucleotides and Nucleic Acids. 31;23(8-9):1287-93.

11. Adinolfi E, Callegari MG, Ferrari D, Bolognesi C, Minelli M, Wieckowski MR, et al. (2005) Basal activation of the P2X7 ATP receptor elevates mitochondrial calcium and potential, increases cellular ATP levels, and promotes serum-independent growth. Molecular Biology of the Cell. 16(7):3260-72.

12. Gendaszewska-Darmach E, Szustak M. (2016) Thymidine 5'-Omonophosphorothioate induces HeLa cell migration by activation of the P2Y6 receptor. Purinergic Signalling. 12(2):199-209.

13. Merighi S, Mirandola P, Varani K, Gessi S, Leung E, Baraldi PG, et al. (2003) A glance at adenosine receptors: novel target for antitumor therapy. Pharmacology \& Therapeutics. 100(1):31-48.
14. Sharma S, Kalra H, Akundi RS. (2020) Extracellular ATP mediates cancer cell migration and invasion through increased expression of cyclooxygenase. Frontiers in Pharmacology. 11:617211.

15. Muñóz-Godínez R, de Lourdes MGM, Weiss-Steider B, Montesinos-Montesinos JJ, del Carmen ALA, García-Rocha R et al. (2020) Detection of CD39 and a Highly Glycosylated Isoform of Soluble CD73 in the Plasma of Patients with Cervical Cancer: Correlation with Disease Progression. Mediators of Inflammation.

16. Joyner MJ, Carter RE, Senefeld JW, Klassen SA, Mills JR, Johnson PW et al. (2021) Convalescent plasma antibody levels and the risk of death from covid-19. New England Journal of Medicine. 384(11):1015-1027.

17. Sriram K, Insel, PA. (2020) Inflammation and thrombosis in COVID-19 pathophysiology: proteinase-activated and purinergic receptors as drivers and candidate therapeutic targets. Physiological Reviews. 101(2):545-567.

18. Kanthi Y, Knight JS, Zuo Y, Pinsky DJ. (2020) New (re) purpose for an old drug: purinergic modulation may extinguish the COVID-19 thromboinflammatory firestorm. JCI insight. 23;5(14):e140971.

19. Cardoso AM. (2020) COVID-19 and purinergic signaling: the need for investigation. Purinergic Signalling. 16(3):451-452.

20. Geiger JD, Khan N, Murugan M, Boison D. (2020) Possible role of adenosine in COVID-19 pathogenesis and therapeutic opportunities. Frontiers in pharmacology. 11:594487.

21. Nagar H, Formenti SC. (2020) Cancer and COVID-19potentially deleterious effects of delaying radiotherapy. Nature Reviews Clinical Oncology. 17(6), 332-334.

22. Ginsburg O, Basu P, Kapambwe S, Canfell K. (2021) Eliminating cervical cancer in the COVID-19 era. Nature Cancer, 144:106294.

23. Miriyala R, Mahantshetty U. (2020) Brachytherapy in cervical cancer radiotherapy during COVID-19 pandemic crisis: problems and prospects. Journal of Contemporary Brachytherapy. 12(3):290-293.

24. Cohen MA, Powell AM, Coleman JS, Keller JM, Livingston A, Anderson JR. (2020) Special ambulatory gynecologic considerations in the era of coronavirus disease 2019 (COVID-19) and implications for future practice. American journal of obstetrics and gynecology. 223(3), 372-378.

25. De Santiago J, Yelo C, Chereguini MF, Conde A, Galipienzo J, Salvatierra D et al. (2020) COVID-19: gynecologic cancer surgery at a single center in Madrid. International Journal of Gynecologic Cancer. 30(8):1108-1112.
This work is licensed under Creative Commons Attribution 4.0 License

To Submit Your Article Click Here: Submit Manuscript

DOI: $10.31579 / 2640-1053 / 084$
Ready to submit your research? Choose Auctores and benefit from:
fast, convenient online submission
rigorous peer review by experienced research in your field
authors retain copyrights
- imique DOI for all articles
immediate, unrestricted online access

At Auctores, research is always in progress.

Learn more www.auctoresonline.org/journals/cancer-research-andcellular-therapeutics 